\title{
SOBRE A OCORRÊNCIA DE CETÁCEOS NO LITORAL DO ESTADO DO RIO DE JANEIRO, ENTRE 1968 E 1984
}

\author{
Geise, L.* \\ Borobia, M.*
}

\begin{abstract}
In this paper some data are shown about cetaceans that occurred at the Rio de Janeiro coast from 1968 to 1984. The newspapers' archives were used, as well as personal observations. There are some new records and the greatest number of animals were seen during August.
\end{abstract}

\section{INTRODUÇÃO}

Baleias e golfinhos encalham freqüentemente, naturalmente ou não. Em mortalidade natural incluiríamos os encalhes por doenças, por suicídio (causado provavelmente quando acuados por sons estranhos), por tubarões, por se alimentarem perto da linha de maré ou por desorientação pelo não reconhecimento dos sinais de eco provenientes de regiões costeiras não conhecidas (Slijper, 1962; Geraci, 1978; Sergeant, 1982). Em mortalidade não natural `stariam os ferimentos causados pela caça, acidentes provocados por atividades humanas (atropelamento por barcos, captura acidental por redes e poluição química). Encalhes em massa ocorrem somente em odontocetos, provavelmente como resultado do sistema social avançado destas espécies.

A escassez de informações corretas que permitam traçar a distribuição, ou pelo menos, listar corretamente as espécies que ocorrem no litoral brasileiro é bastante acentuada, exceto listagens de Vieira (1955), Carvalho (1975) e Bittencourt (1984), nada mais foi relatado.

Torna-se portanto essencial que todos os dados sobre animais encal'hados ou avistados sejam colhidos. Os encalhes representam uma importante fonte de informações sobre a biologia (Geraci \& St. Aubin, 1977), permitindo estudos sobre reprodução, crescimento e maturação.

Neste trabalho resumimos dados pessoais sobre cetáceos avistados e coletados a partir de 1981 e de um levantamento retrospectivo, baseando-nos nos arquivos dos principais jornais da cidade do Rio de Janeiro (O Globo, Jornal do Brasil, O Dia e Última Hora), já que estes conseguem reunir dados importantes, bem como o registro fotográfico.

* Fundação Brasileira para a Conservação da Natureza (FBCN) Rua Miranda Valverde, n. 103 - Rio de Janeiro - RJ - Brasil. 


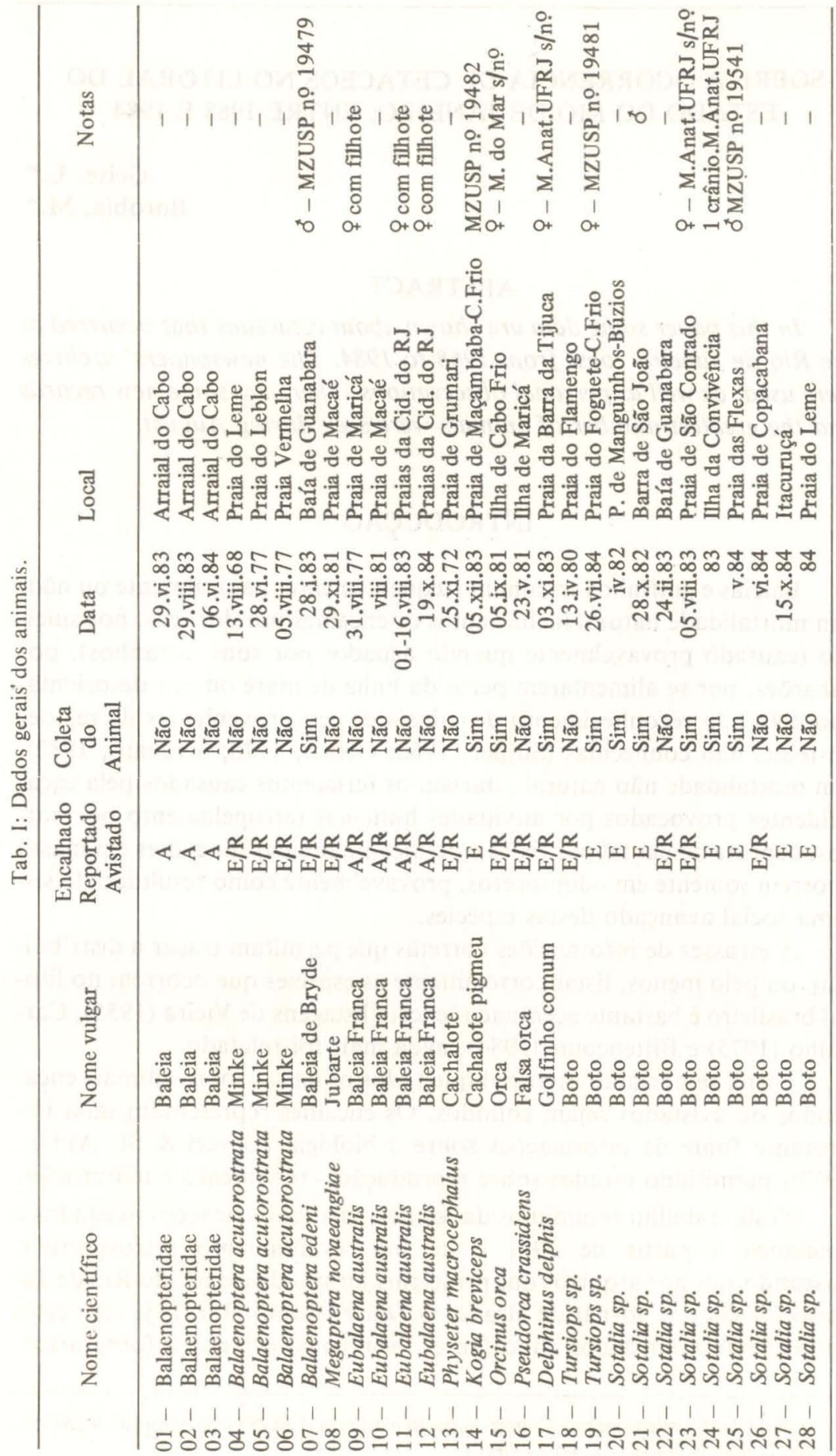




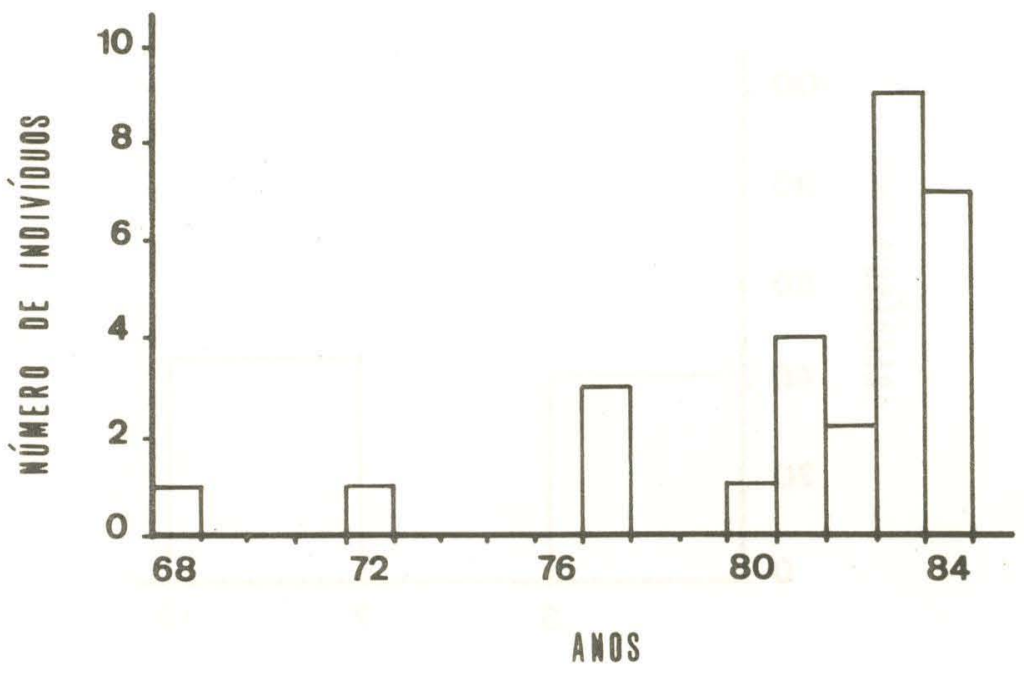

Fig. 1: Incidência de animais ao longo dos 17 anos.

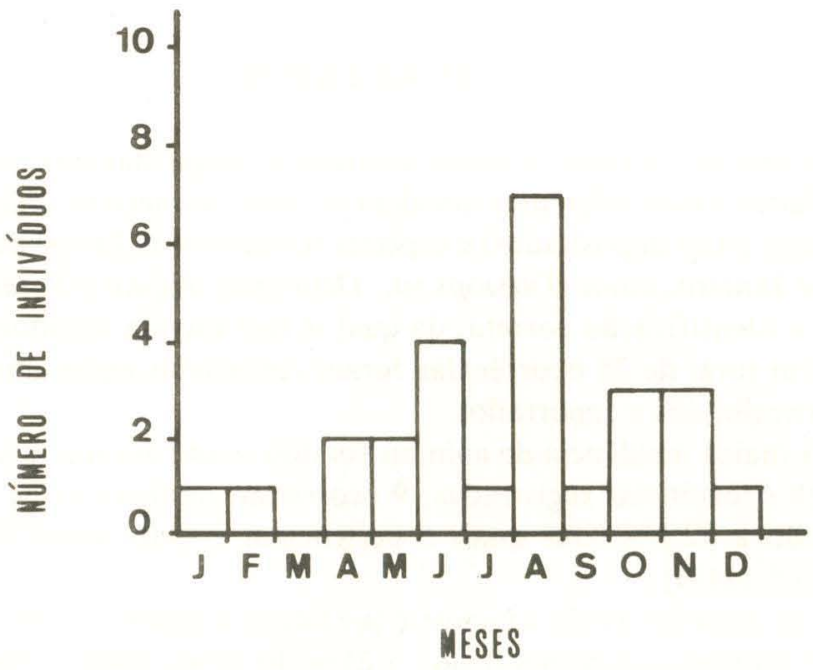

Fig. 2: Incidência de animais nos diferentes meses. 


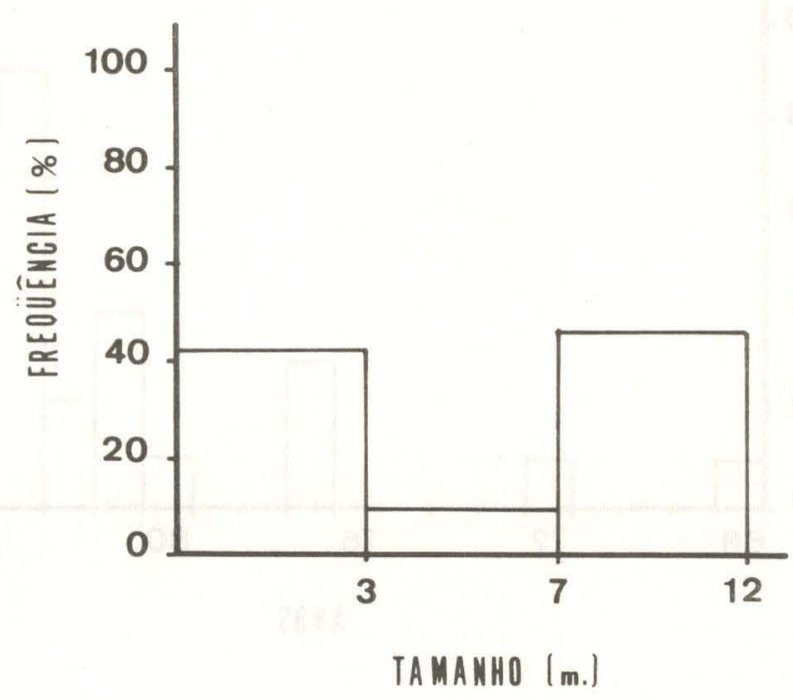

Fig. 3: Freqüência $(\%)$ de animais com menos de 3 metros, entre 3 e 7 metros e de até 12 metros.

\section{RESULTADOS}

A tabela I fornece o nome científico e vulgar das espécies encontradas, dados a elas referentes (localidade, data, número de registro do museu onde estão depositados) e espécies residentes no litoral do Estado do Rio de Janeiro, como Tursiops sp., Delphinus delphis e Sotalia sp. (pendente a identificação correta, da qual se tem dúvida taxonomicamente).

Um total de 28 ocorrências foram registradas entre animais avistados, encalhados e reportados.

A maior incidência de animais foi observada durante o ano de 1983. Das 28 ocorrências registradas, 9 ocorreram neste ano (Fig. 1), correspodendo a $32,2 \%$, das quais 5 pertenciam a Odontoceti $(56 \%)$ e 4 a Misticeti (44\%).

Foi durante o mês de agosto que houve a maior incidência (Fig. 2), com 7 animais, correspondendo a $25 \%$ do total, sendo 6 misticetos e 1 odontoceto, respectivamente $86 \%$ e $14 \%$ das ocorrências nesse mês.

Obteve-se uma freqüência de $46 \%$ para animais entre 7 e 12 metros de comprimento, enquanto que para aqueles com tamanho de até 3 metros e de 3 à 7 metros, obteve-se $43 \%$ e 10,7\% respectivamente (Fig. 3). 


\section{DISCUSSÃO}

Todas as espécies abordadas encontram-se na lista de mamíferos marinhos do Brasil (Carvalho, 1975), ou na lista de identificação de cetáceos (Bittencourt, 1984); Kogia breviceps, Physeter macrocephalus, Orcinus orca e Pseudorca crassidens constituem primeiros registros para o litoral do Estado do Rio de Janeiro; Balaenoptera acutorostrata, Balaenoptera edeni e Eubalaena australis confirmam que este litoral está incluído na rota migratória.

Estas informações indicam a validade do uso de arquivos de jornais como um meio para obtenção de dados, possibilitando, em alguns casos, a identificação a nível específico, como a de Balaenoptera acutorostrata, Megaptera novaeangliae, Eubalaena australis e Pseudorca crassidens.

A maior freqüência de misticetos $(86 \%)$ durante agosto está relacionada com o hábito migratório destas grandes baleias, que se dirigem para águas quentes e tropicais durante o inverno antártico (Lockley, 1979). Esta migração tem a finalidade de reprodução, período durante o qual não se alimentam. Portanto, é de se esperar que nessa época ocorram no nosso litoral.

Por outro lado, depara-se com o problema de que geralmente os animais reportados são aqueles cujas dimensões despertem a atenção do público, como por exemplo as baleias. As ocorrências de botos e golfinhos passam desapercebidas e não são registradas tão freqüentemente pelos jornais, a não ser que se trate de um encalhe em massa, o que nunca foi registrado em nossa costa. Conseqüentemente, surge uma diferença acentuada entre o número de indivíduos reportados com mais ou menos 3 metros e os maiores, com 7 metros.

\section{AGRADECIMENTOS}

Agradecemos aos jornais do Rio de Janeiro, por terem permitido a utilização de seus arquivos. Ao Lic. Hugo P. Castello e Robin C. Best, pelo auxílio na identificação correta das espécies, ao Dr. Ubirajara R. Martins, pela revisão do texto e todos amigos que nos alertaram da presença de alguns animais.

\section{REFERENNCIAS}

Bittencourt, M. L., 1984. Contribuições para a identificação dos cetáceos na costa e águas interiores do Brasil. Arq. Biol. Tecnol., 27 (4): 529-547.

Carvalho, C. T., 1975. Ocorrência de mamiferos marinhos no Brasil. Bol. Téc. I. F., S. Paulo, 16: 13-32.

Geraci, J. R. \& St. Aubin, D. J., 1977. Mass stranding of the longfinned pilot whale, Globicephala melaena on Sable Island, Nova Scotia. J. Fish. Res. Board. Can., 34: 2196-2199. Geraci, J. R., 1978. The enigma of marine mamals stranding. Oceanus, 21 (2): 38-47. 
Lockley, R. M., 1979. Whales, dolphins and porpoises. David \& Charles; Newton Abbot: London.

Sergeant, D.E., 1982. Mass strandings of toothed whales (Odontoceti) as a population phenomenon. Sci. Rep. Whales Res. Inst., 34: 1-47.

Slijper, E. J., 1962. Whales. 1-511. Cornell University, Ithaca, New York.

Vieira, C. da C., 1955. Lista remissiva dos mamíferos do Brasil. Arq. de Zool., S. Paulo, 8 (11), 430-456. 